\title{
Faktor Sikap dan Perilaku yang Berhubungan dengan Malaria di Wilayah Kerja Puskesmas Banjarmangu I Banjarnegara
}

\author{
Siti Thomas Zulaikhah“, Menik Sahariyani, Prasetyo Bhakti H, David Akbar M, \\ Mustika Rani \\ Fakultas Kedokteran, Universitas Islam Sultan Agung, Semarang, Indonesia \\ *Corresponding author, e-mail: sitithomas@unissula.ac.id
}

Received: 11/12/2019; Published: 18/03/2020

\begin{abstract}
Background: Malaria is an infectious disease caused by Plasmodium and transmitted to humans through the bite of infected female Anopheles. Characteristics of a person affecting the pattern of life that can contribute to the occurrence, attitudes and behaviors that is less attention to environmental related to Anopheles population can contribute to the malaria. In Indonesia, malaria is found in almost all regions. Some provinces are still malaria endemic areas, both low, medium and high. The number of malaria-based illnesses in API in Central Java in 2014 was recorded at 0.05 per 1000 population, and indigenous cases were still found in 5 districts, namely Purworejo, Banjarnegara, Purbalingga, Banyumas and Kebumen. Banjarnegara is one of the district in Central Java which is an endemic area of malaria, the patients as many 247, of that 102 patients in Puskesmas Banjarmangu I, Banjarmangu. This study aims to related factors attitude and behavior to the malaria. Method: The research was observasional analytic with case control design. The sample of 34 cases and 34 controls, with simple random sampling. Attitudes and behaviors were examined using logistic regression. Results: The result of study showed that attitude ( $p=0,015 ; O R=3,656 ; 95 \% C l=1,292-10,344)$ and behavior ( $p$ $=0,031 ; O R=2,962 ; 95 \% \mathrm{Cl}=1,104-7,942)$ were significance relationship with malaria. Conclusion: Attitude and behavior related to the malaria in working area of Banjarmangu I, Banjarnegara. The dominant factors was attitude.
\end{abstract}

Keywords: malaria; attitude; behavior; banjarnegara

Copyright $\odot 2013$ Universitas Ahmad Dahlan. All rights reserved.

\section{Pendahuluan}

Malaria merupakan penyakit infeksi, penyebabnya adalah parasit sporozoa yaitu Plasmodium yang ditularkan ke manusia melalui gigitan nyamuk Anopheles betina infektif. Di Indonesia, ditemukan hampir di semua wilayah.(1) Insiden malaria pada penduduk Indonesia tahun 2013 adalah 1,9\% menurun dibanding tahun 2007 (2,9\%).(2) Beberapa provinsi masih menjadi daerah endemis malaria baik rendah, sedang maupun tinggi. Angka kesakitan malaria berdasarkan API di Jawa Tengah pada tahun 2014 tercatat 0,05 per 1000 penduduk, ditemukan kasus indigenous di 5 Kabupaten yaitu Banjarnegara, Purworejo, Purbalingga dan Banyumas Kebumen.(3) Di Provinsi Jawa Tengah, salah satu daerah endemis malaria dengan kasus indigenous adalah Kabupaten Banjarnegara. Tahun 2010-2014 angka kesakitan malaria (Annual Parasite Incidence) Kabupaten Banjarnegara mengalami penurunan, yaitu pada tahun 2012 0,6\%o menjadi 0,42\%o di tahun 2013, jumlah kasus malaria sebanyak 407 kasus dan mengalami penurunan kembali menjadi 0,285\%o dengan jumlah kasus malaria pada tahun 2014 sebanyak 207 kasus.(4) Sepanjang tahun 2015, jumlah penderita malaria sebanyak 247 penderita, dari jumlah tersebut 102 penderita berasal dari wilayah kerja Puskesmas Banjarmangu I, yang terdistribusi di Desa Paseh 53 kasus, 23 kasus di Desa Sigeblog dan 26 kasus di Desa Pekandangan.(4) Wilayah kerja Puskesmas Banjarmangu I merupakan salah satu daerah 
Kecamatan Banjarmangu Kabupaten Banjarnegara yang memiliki tingkat kejadian malaria tertinggi dalam 2 tahun terakhir.(4)

Faktor terbesar kedua setelah faktor lingkungan yang mempengaruhi kesehatan individu, kelompok, atau masyarakat adalah perilaku. Teori L-Green mengatakan bahwa perilaku dipengaruhi oleh faktor predisposisi yaitu pengetahuan, sikap dan kebiasaan.(5) Malaria merupakan salah satu masalah kesehatan masyarakat yang dapat menyebabkan kematian terutama pada kelompok risiko tinggi yaitu bayi, anak balita, ibu hamil, selain itu malaria secara langsung menyebabkan anemia dan dapat menurunkan produktivitas kerja.(6) Hasil penelitian Saha et all menyatakan bahwa pengetahuan yang tinggi tentang malaria berkorelasi dengan sikap positif terhadap malaria.(7)

Karakteristik seseorang mempengaruhi pola kehidupan yang dapat berkontribusi pada terjadinya suatu penyakit, terkait dengan populasi nyamuk Anopheles dapat berkontribusi pada tingginya kejadian malaria. Hasil penelitian sebelumnya menyatakan bahwa jenis kelamin penderita malaria $73,33 \%$ laki-laki, hal ini berhubungan dengan aktifitas dan pekerjaan masyarakat seperti petani dan kebiasaan keluar rumah hingga larut malam.(8)

Penelitian selanjutnya menyatakan bahwa kebiasaan beraktivitas di luar rumah berisiko tertular malaria sebesar 4,724 kali, kebiasaan tidak menggunakan obat nyamuk berisiko terserang malaria 3,343 kali.(9) Hasil penelitian lain menyatakan bahwa ada hubungan sikap dan perilaku dengan derajat infeksi penderita malaria falciparum baru di wilayah kerja Puskesmas Hanura Kecamatan Teluk Pandan Kabupaten Pesawaran Provinsi Lampung.(10) Tujuan penelitian untuk mengidentifikasi faktor sikap dan perilaku yang paling dominan berhubungan dengan malaria.

\section{Metode}

Jenis penelitian adalah observasional analitik dengan rancangan case-control.(11) Populasi penelitian ini adalah masyarakat yang menderita malaria wilayah kerja Puskesmas Banjarmangu 1, Kecamatan Banjarmangu, Kabupaten Banjarnegara yang tercatat pada tahun 2016-2017. Sampel kasus adalah pasien secara klinis dan laboratorium didiagnosis menderita malaria serta tercatat dalam medical record dari bulan september 2016 sampai dengan september 2017. Kontrol adalah masyarakat di wilayah kerja Puskesmas Banjarmangu I, Kecamatan Banjarmangu, Kabupaten Banjarnegara yang tidak sakit malaria dan merupakan tetangga kasus yang mempunyai karakteristik seperti usia, jenis kelamin, pendidikan dan pekerjaan yang sama dengan kasus. Teknik sampling yang digunakan simple random sampling. Besar sampel dihitung berdasarkan rumus dari Sopiyudin, dimana hasil perhitungan diperoleh $n=34$, jadi ditetapkan 34 sampel kasus dan 34 kontrol.(12) Teknik pengambilan sampel secara random (simple random sampling) yaitu berdasarkan tanggal sakit medical record Puskesmas Banjarmangu I Banjarnegara.

Sikap responden diukur dengan 10 pertanyaan, dimana jawaban sangat setuju mendapat skor 3 , setuju 2, kurang setuju 1 dan tidak setuju 0 , total skor minimum 0 dan maksimum 30, yang dikelompokkan menjadi 2 yaitu kurang (apabila total skor $\leq 15$ ) dan baik (apabila total skor $>15$ ). Perilaku kesehatan diukur dengan 12 pertanyaan, dimana jawaban ya mendapat skor 1 dan tidak 0 , total skor minimum 0 dan maksimum 12 , yang dikelompokkan menjadi kurang (jika total skor $\leq 6$ ) dan baik (jika total skor $>6$ ). Kuesioner untuk sikap dan perilaku sudah dilakukan uji validitas dan reliabilitas terhadap 30 responden yang berada di wilayah Banjarmangu dengan hasil valid $(r>0,361)$ dan reliabel ( $\alpha$ Cronbath $=0,891$ ). Analisis data dilakukan secara univariat menggunakan distribusi frekuensi, bivariat menggunakan uji Chi Square dan multivariat menggunakan regresi logistik.(13) 


\section{Hasil dan Pembahasan}

\subsection{Hasil}

Tabel 1. Menunjukkan bahwa berdasarkan jenis kelamin, laki-laki di kelompok kasus dan di kelompok kontrol berjumlah sama yaitu $64,7 \%$, pendidikan pada kelompok kasus dan kontrol sebagian besar lulus SD (kasus 38,2\% dan kontrol 41,2\%), responden pada kelompok kasus sebagian besar bekerja sebagai IRT $(29,4 \%)$ dan pada kelompok kontrol sebagian besar bekerja sebagai petani $(26,5 \%)$. Umur, jenis kelamin, pendidikan pada kelompok kasus dan kelompok kontrol tidak ada perbedaan yang signifikan ( $p$-value $>0,05)$, tetapi pekerjaan pada kelompok kasus dan kelompok kontrol ada perbedaan yang signifikan ( $p$-value<0,05).

Tabel 1. Distribusi Frekuensi Karakteristik Responden di Wilayah Kerja Puskesmas Banjarmangu I Kabupaten Banjarnegara

\begin{tabular}{cccc}
\hline Karakteristik & Kasus & Kontrol & P-value \\
\hline Umur (mean \pm SD) & $37,82 \pm 14,31$ & $35,65 \pm 11,57$ & 0,777 \\
Jenis kelamin & & & \\
Laki-laki & $22(64,7 \%)$ & $22(64,7 \%)$ & 1,000 \\
Perempuan & $12(35,3 \%)$ & $12(35,3 \%)$ & \\
Pendidikan & & & \\
SD & $13(38,2 \%)$ & $14(41,2 \%)$ & \\
SMP & $12(35,3 \%)$ & $11(32,4 \%)$ & 0,442 \\
SMA & $7(20,6 \%)$ & $6(17,6 \%)$ & \\
SMK & $1(2,9 \%)$ & $1(2,9 \%)$ & \\
S1 & $1(2,9 \%)$ & $2(5,9 \%)$ & \\
Pekerjaan & $4(11,8 \%)$ & $6(17,6 \%)$ & \\
Buruh & $7(20,6 \%)$ & $9(26,5 \%)$ & \\
Petani & $3(8,8 \%)$ & $1(2,9 \%)$ & \\
Guru & $10(29,4 \%)$ & $5(14,7 \%)$ & 0,046 \\
IRT & $1(2,9 \%)$ & $0(0,0 \%)$ & \\
Mahasiswa & $1(2,9 \%)$ & $4(11,8 \%)$ & \\
Pedagang & $1(2,9 \%)$ & $1(2,9 \%)$ & \\
PNS & $4(11,8 \%)$ & $8(23,5 \%)$ & \\
Swasta & $3(8,8 \%)$ & $0(0,0 \%)$ & \\
Tidak bekerja & & & \\
\hline
\end{tabular}

Berdasarkan Tabel 2. diketahui bahwa terdapat hubungan sikap dengan kejadian malaria, dimana responden yang memiliki sikap kurang baik berisiko 3,7 kali lebih besar untuk menderita malaria dibandingkan dengan responden yang memiliki sikap baik ( $p$ value $<0,05 ; \mathrm{OR}=3,656 ; 95 \% \mathrm{Cl}=1,292-10,344$ ). Selain itu, juga ada hubungan antara perilaku kesehatan dengan kejadian malaria, dimana responden yang memiliki perilaku kesehatan kurang berisiko 2,962 kali lebih tinggi untuk menderita malaria dibandingkan dengan responden yang memiliki perilaku kesehatan baik ( $p$-value $<0,05 ; \quad \mathrm{OR}=2,962$; $95 \% \mathrm{Cl}=1,104-7,942)$. Variabel yang paling dominan berhubungan dengan kejadian malaria adalah sikap ( $p$-value $<0,05 ; \mathrm{OR}=6,56 ; 95 \% \mathrm{Cl}=2,92-10,34)$.

Tabel 2. Hasil Analisis Multivariat Sikap dan Perilaku Kesehatan dengan Kejadian Malaria di Wilayah Kerja Puskesmas Banjarmangu I

\begin{tabular}{lccccc}
\hline Variabel & Crude OR & $\mathbf{9 5 \%} \mathbf{C l}$ & $\begin{array}{c}\text { Adjusted } \\
\text { OR }\end{array}$ & $\mathbf{9 5 \%} \mathbf{C l}$ & p-value \\
\hline $\begin{array}{c}\text { Sikap } \\
\quad \text { Kurang Baik } \\
\text { Baik }\end{array}$ & 3,656 & $1,292-10,344$ & 6,56 & $2,92-10,34$ & 0,015 \\
$\begin{array}{c}\text { Perilaku Kesehatan } \\
\text { Kurang } \\
\text { Baik }\end{array}$ & 2,962 & $1,104-7,942$ & 4,62 & $1,90-7,94$ & 0,031 \\
\hline
\end{tabular}




\subsection{Pembahasan}

Sikap masyarakat dalam penelitian ini terbukti menjadi faktor risiko terhadap kejadian malaria. Sikap adalah respon atau reaksi respon yang masih tertutup dari seseorang terhadap stimulus atau objek. Sikap bukan merupakan tindakan atau perilaku, tetapi sikap dapat mempengaruhi perilaku karena sikap merupakan predisposisi tindakan suatu perilaku.(5) Penelitian ini dapat menunjukkan adanya hubungan sikap dengan perilaku kesehatan masyarakat, dan karena kemampuan sikap dalam memstimulasi perilaku kesehatan ini maka sikap dapat berkontribusi pada kejadian malaria. Penelitian yang linier dengan hasil penelitian bahwa ada hubungan antara sikap dengan kejadian malaria. $(14,15)$

Masyarakat yang menderita malaria di wilayah kerja Puskesmas Banjarmangu I cenderung memiliki sikap yang kurang baik jika dibandingkan dengan masyarakat yang tidak menderita malaria. Hal ini tampak dari sikap yang kurang baik pada indikator menghindari gigitan nyamuk untuk mencegah malaria, memasang kawat kasa pada ventilasi lingkungan, menyemprotkan insektisida ke dinding rumah, membawa anggota keluarga yang demam ke layanan kesehatan, dan menyarankan kepada penderita malaria untuk menghabiskan obat untuk mencegah kekambuhan.

Perilaku kesehatan dalam penelitian ini terbukti berhubungan dengan kejadian malaria. Perilaku kesehatan yang buruk pada masyarakat yang terkait dengan kejadian malaria diantaranya adalah membiasakan menggantung baju bekas pakai di dalam rumah, sehingga baju-baju tersebut digunakan oleh vektor malaria nyamuk Anopheles sp. sebagai tempat hinggap, berlindung dan beristirahat. Membiarkan genangan air dan vegetasi (semak-semak) di sekitar rumah kotor juga berkontribusi pada meningkatnya kejadian malaria pada masyarakat, perilaku buruk lainnya terkait dengan kejadian malaria adalah mempunyai kebiasaan keluar rumah pada malam hari, kebiasaan menggantung baju bekas di dalam rumah, keberadaan tempat perindukan nyamuk, tidak memasang kawat kasa pada ventilasi rumah yang dapat berkontribusi pada meningkatnya populasi dan frekuensi gigitan nyamuk Anopheles sp. sehingga morbiditas akibat penyakit malaria juga meningkat, ada hubungan antara faktor-faktor tersebut dengan malaria.(10) Penelitian yang dilakukan di Kecamatan Panyabungan Mandailing Natal Sumatera Utara menyatakan bahwa faktor risiko yang dominan terhadap kejadian malaria adalah tidak menggunakan obat anti nyamuk dan kelambu, kebiasaan menggunakan pakaian yang tidak rapat ketika keluar rumah pada malam hari serta keluar rumah.(16) Penelitian Santi et al., (2014) juga telah menunjukkan bahwa kebiasaan pemakaian kelambu, pemakaian obat anti nyamuk dan kebiasaan beraktivitas di luar rumah pada malam hari berhubungan dengan kejadian malaria.(17)

Hasil penelitian ini relevan dengan teori H.L. Blum bahwa derajat kesehatan individu ataupun sekelompok masyarakat dipengaruhi oleh empat faktor, yaitu lingkungan, perilaku, pelayanan kesehatan dan keturunan. Perilaku memiliki kontribusi lebih besar daripada faktor lainnya untuk negara berkembang seperti Indonesia. Perilaku kesehatan masyarakat sendiri dipengaruhi oleh sikap masyarakat dan perilaku tersebut dapat mempengaruhi lingkungan yang terdapat di sekitar manusia.(5)

Penelitian ini didukung oleh penelitian yang menyatakan bahwa terdapat hubungan perilaku masyarakat dengan kejadian malaria. $(14,15)$ Perilaku kesehatan masyarakat di wilayah kerja Puskesmas Banjarmangu I yang baik ini ditunjukkan oleh sebagian besar masyarakat yang telah memasang kelambu pada tempat tidur untuk mencegah nyamuk mendekat, menggunakan obat antinyamuk setiap akan tidur untuk menghindari gigitan dan mengusir nyamuk, menggunakan pelindung antinyamuk saat beraktivitas luar rumah, memasang kawat kasa pada setiap ventilasi rumah, tidak sering menggantung baju bekas pakai di dalam rumah, membersihkan semak-semak setiap hari, mengupayakan tempat 
sampahnya bersih dan tertutup, memelihara ikan di kolam/danau, membersihkan bagian dalam dan halaman rumah (termasuk kandang ternak), mencuci tirai gordern sebulan sekali, dan menguruk lubang cekungan yang berisi air. Di antara berbagai indikator perilaku kesehatan tersebut, sebagian besar kasus (55,9\%) tidak menutup lubang cekungan yang berisi air. Lubang/cekungan berisi air yang tidak diurug menjadi tempat habitat yang disukai oleh vektor nyamuk Anopheles untuk tumbuh dan berkembang biak. Perkembangbiakan nyamuk Anopheles sp juga dipengaruhi oleh kondisi dan ukuran rumah18. Wilayah kerja puskesmas Banjarmangu I Kabupaten Banjarnegara ini termasuk dalam dataran tinggi, yang banyak tanaman semak-semak, dimana pada daerah ini Anopheles $s p$ cenderung berkembangbiak pada tempat-tempat yang tidak langsung kontak dengan tanah.(19)

Sikap dan perilaku setelah diuji secara bersama-sama melalui uji multivariat diperoleh hasil bahwa sikap merupakan faktor risiko yang paling dominan berhubungan dengan malaria. Sikap sebagai sebuah kecenderungan untuk bertingkah laku dengan cara tertentu dalam situasi sosial, sikap pada awalnya diartikan sebagai syarat untuk munculnya sebuah tindakan. Sikap merupakan hasil pertimbangan untung dan rugi dari perilaku. Perilaku menurut Theory of Reasoned Action (TRA) dipengaruhi oleh niat, sedangkan niat sendiri dipengaruhi oleh sikap dan norma subyektif. Sikap sendiri dipengaruhi oleh keyakinan, seseorang akan melakukan suatu perbuatan apabila ia memandang perbuatan itu positif dan bila ia percaya bahwa orang lain ingin agar ia melakukannya.(20) Menurut teori L-Green bahwa perilaku sangat dipengaruhi oleh faktor predisposisi seperti pengetahuan, sikap, niat dll.(5)

Pencegahan malaria dapat dilakukan melalui 3 aspek, yaitu melindungi orang yang rentan dan berisiko terinfeksi malaria, pengendalian nyamuk sebagai vektor malaria dan mengurangi penderita yang mengandung gametosit yang merupakan sumber infeksi (reservoir). Penderita malaria akut diobati dengan obat yang efektif terhadap fase awal dari siklus eritrosit aseksual sehingga gametosit tidak sempat terbentuk di dalam darah penderita merupakan cara pencegahan penularan kepada orang lain. Pengendalian nyamuk dapat dilakukan dengan membunuh larva dan nyamuk dewasa, pengisian/pengurukan/penutupan lubang-lubang yang mengandung air, drainase tempat perindukan, pemberantasan tempat perindukan nyamuk.(21)

Masih ada responden $(11,8 \%)$ pada kasus yang tidak setuju dengan memelihara kebersihan rumah dan lingkungan, disebabkan oleh karena pengetahuan yang kurang mengenai pencegahan malaria. Hal ini terlihat dari responden kasus yang tidak menggunakan kelambu $(73,5 \%)$ sesuai dengan fungsinya. Sikap berhubungan dengan perilaku pencegahan malaria.(22) Hasil ini juga sesuai dengan penelitian Engkeng dan Roy yang menyatakan bahwa terdapat hubungan antara sikap dengan tindakan cara pencegahan malaria pada masayarakat di desa Jiko Utara Kecamatan Nuangan Kabupaten Bolaang Mongondow Timur.(23)

Penelitian di Ethiophia, menyatakan bahwa seluruh responden mempunyai kelambu, Namun, mayoritas dari mereka $(68,1 \%)$ tidak sering menggunakan kelambu. Kegagalan dalam menggunakan kelampu yang dimiliki di antara masyarakat mungkin disebabkan oleh kurangnya kesadaran tentang penggunaannya yang tepat dan efektivitasnya dalam mencegah gigitan nyamuk.(24) Penelitian yang dilakukan di Rumah Sakit Tumbi menyatakan bahwa sekitar $95 \%$ individu menggunakan kelambu pada saat tidur, hal ini mencerminkan bahwa responden memiliki sikap yang mendukung dan perilaku yang baik tentang pencegahan dan pengendalian malaria.(25) Ada hubungan antara tingkat pengetahuan dengan kejadian malaria $(\mathrm{p}=0,002 ; \mathrm{OR}=2,45)$ dan perilaku dengan kejadian malaria ( $p=0,002 ; O R=9,28)$.(26) Ada hubungan antara pengetahuan dengan perilaku responden terhadap peningkatan kasus malaria $(p=0,04),(27)$ kondisi lingkungan dan status sosial ekonomi juga berhubungan dengan kejadian malaria.(28) 


\section{Kesimpulan}

Berdasarkan hasil penelitian dapat disimpulkan bahwa sikap dan perilaku berhubungan dengan kejadian malaria. Kepada masyarakat agar lebih peduli terhadap pencegahan penyakit malaria, khususnya terhadap perilaku seperti menggunakan kelambu pada saat tidur, memasang kawat kasa pada lubang ventilasi untuk menurunkan populasi nyamuk Anopheles sp. Kepada dinas terkait agar meninjau kembali keefektifan program pengendalian yang telah dilaksanakan dan secara rutin melakukan penyuluhan tentang pengendalian nyamuk sebagai vektor malaria untuk meningkatkan perilaku masyarakat dalam mencegah malaria.

\section{Daftar Pustaka}

1. Widoyono. Penyakit Tropis: Epidemiologi, Penularan, Pencegahan dan Pemberantasannya. Ed. 2. Jakarta: Penerbit Erlangga. 2018.

2. Kementerian Kesehatan Republik Indonesia. Riset Kesehatan Dasar 2018. Jakarta. 2018.

3. Dinas Kesehatan Jawa Tengah. Profil Kesehatan Provinsi Jawa Tengah Tahun 2015, Dinas Kesehatan Provinsi Jawa Tengah, Semarang. 2015.

4. Dinas Kesehatan Banjarnegara. Profil Kesehatan Tahun 2014. Dinas Kesehatan, Banjarnegara. 2015.

5. Notoatmodjo. Promosi kesehatan dan Perilaku Kesehatan. Jakarta: PT Rineka Cipta. 2012.

6. Kemenkes RI. Buletin Jendela Data dan Informasi Kesehatan Epidemiologi Malaria di Indonesia. Triwulan I. 2011.

7. Saha A, Sarker M, Kabir M, Lu G, Müller O. Knowledge, attitudes, and practices regarding malaria control among the slash and burn cultivators in Rangamati Hill tracts of Bangladesh. Malar J. 2019;18(1):1-9.

8. Kotepui M, Punsawad C, Kotepui KU, Somsak V, Phiwklam N, Phunphuech B.

Prevalence of malarial recurrence and hematological alteration following the initial drug regimen: A retrospective study in Western Thailand. BMC Public Health. 2019;19(1):1-8.

9. Junaidi H, Mursid R. Onny S. Analysis of Risk Factors of Malaria incidence in the Working Area of Kuala Bhee Public Health Center in Woyla District, West Aceh. Jurnal Kesehatan Lingkungan Indonesia. 2015;14(2):40-44.

10. Nurmaulina W, Kurniawan B, Fakhruddin H. Hubungan Pengetahuan, Sikap dan Perilaku Penderita Malaria Falciparum Dengan Derajat Infeksi di Wilayah Kerja Puskesmas Hanura Kecamatan Teluk Pandan Kabupaten Pesawaran Provinsi Lampung. Majority. 2018;7(3):34-40.

11. Sastroasmoro S, Ismael S. Dasar-Dasar Metodologi Penelitian Klinis. 5 ed. Jakarta: Sagung Seto. 2015..

12. Dahlan MS. Besar Sampel dan Cara Pengambilan Sampel dalam Penelitian Kedokteran dan Kesehatan. 4 ed. Jakarta: Salemba Medika. 2016.

13. Dahlan MS. Pintu Gerbang Memahami Statistik, Metodologi dan Epidemiologi. Ed.2. Jakarta: Sagung Seto. 2017.

14. Sir O, Arsine A, Syam I, Despitasari M. Faktor-Faktor yang Berhubungan dengan Kejadian Malaria di Kecamatan Kabola, Kabupaten Alor, Provinsi Nusa Tenggara Timur (NTT) Tahun 2014, Jurnal Ekologi Kesehatan. 2015;14(4):334-341.

15. Ajami W.A, Ottay R.I, Rombot D.V. Hubungan antara Perilaku Masyarakat dengan Kejadian Malaria di Wilayah Kerja Puskesmas Tombatu Kabupaten Minahasa Tenggara. Jurnal Kedokteran Komunitas dan Tropik. 2016;4(1):65-72.

16. Rangkuti AF., Sulistyani, NurEndah W. Faktor Lingkungan dan Perilaku yang Berhubungan dengan Kejadian Malaria di Kecamatan Panyabungan Mandailing Natal Sumatera Utara. BALABA. 2017;13(1):1-10.

17. Santy, Fitriangga A, Natalia D. Hubungan Faktor Individu dan Lingkungan dengan Kejadian Malaria di Desa Sungai Ayak 3 Kecamatan Belitang Hilir, Kabupaten Sekadau, eJKI. 2014;2(1):265-272.

18. Essendi WM, Vardo-Zalik AM, Lo E, Machani MG, Zhou G, Githeko AK, et al., 
Epidemiological risk factors for clinical malaria infection in the highlands of Western Kenya. Malar J. 2019;18(1):1-7.

19. Indriyati L, Rosanji A, Juhairiyah, Yuana W.T, Haryati E. Habitat Perkembang biakan Spesifik Anopheles $s p$ di Tambang Emas Kura-Kura Banian (Perubahan Perilaku Anopheles sp), BALABA, 2016;12(2):121-134.

20. Priyono. Teori Sikap dan Perilaku dalam Kesehatan, Yogyakarta: Nuha Medika. 2014.

21. Darmiah, Baserani, Abdul K., Isnawati, Yuniarti S. Hubungan tingkat pengetahuan dan pola perilaku dengan kejadian malaria di Kabupaten Katingan Provinsi Kalimantan Tengah. Journal oh Health Epidemiology and Communicable Diseases. 2017;3(2):36-41.

22. Layan PD., Rahayu H.A, Dina VR.Hubungan antara pengetahuan dan sikap dengan tindakan pencegahan penyakit malaria di wilayah kerja puskesmas bacan timur kabupaten halmahera selatan 2016. Pharmacon Jurnal Ilmiah Farmasi. 2016;5(4):291297.

23. Engkeng S., Roy MDM. Analisis pengetahuan dan sikap dengan tindakan cara pencegahan malaria di desa Jiko Utara Kecamatan Nuangan Kabupaten Bolaang Mongondow Timur. Al-Sihah: Public Health Science Journal. 2017;9:103-111.

24. Alelign A, Petros B. Knowledge, attitudes and practices of malaria transmission and preventive measures in Woreta town, Northwest Ethiopia. BMC Res Notes. 2018;11(1):1-5.

25. Munisi DZ, Nyundo AA, Mpondo BC. Knowledge, attitude and practice towards malaria among symptomatic patients attending Tumbi Referral Hospital: A cross-sectional study. PLoS One. 2019;14(8):1-12.

26. Darmiah, Baserani, Khair A, dkk. Hubungan Tingkat Pengetahuan dan Pola Perilaku dengan Kejadian Malaria di Kabupaten Katingan Provinsi Kalimantan Tengah. J.Health.Epidemiol.Commun.Dis. 2017;3(2):36-41.

27. Pratamawati DA., Widiarti. Gambaran Lingkungan dan Hubungan Pengetahuan, Sikap Dengan Perilaku Pada Peningkatan Kasus Malaria di Desa Kalirejo Kecamatan Kokap Kabupaten Kulonprogo Tahun 2012. Vektora. 2015;7(1):39-48.

28. Guerra M, De Sousa B, Ndong-Mabale N, Berzosa P, Arez AP. Malaria determining risk factors at the household level in two rural villages of mainland Equatorial Guinea. Malar J. 2018;17(1):1-10. 